\title{
Laparoscopic Cholecystectomy at the Korle Bu Teaching Hospital, Accra, Ghana: An Initial Report
}

\section{Cholécystectomie laparoscopique à l'Hôpital universitaire de Korle Bu, Accra, Ghana: Un premier rapport}

\author{
J. N. A Clegg-Lamptey*, G. Amponsah ${ }^{\dagger}$
}

\begin{abstract}
BACKGROUND: Laparoscopic cholecystectomy (LC) the preferred treatment for gallstones was not available in Ghana until 2005.

OBJECTIVE: To report experience from Ghana of laparoscopic cholecystectomy in the treatment of galestones.

METHODS: In a prospective study of patients with gallstones, information was obtained on demography, duration of various stages of the operation, analgesia and complication of patients with gallstones. All patients had general anaesthesia using endotracheal intubation, muscle relaxant and intermittent positive pressure ventilation. A standard four-trocar technique and maximum pneumoperitoneum pressure of $14 \mathrm{mmHg}$ were maintained during surgery.

RESULTS: There were 50 women and two men aged 17-72 years (mean 44.2 years). All had symptomatic gallstones treated by interval LC. The main indications were biliary colic $23(44 \%)$ and previous cholecystitis $15(29 \%)$. There were scars from previous abdominal surgery in $22(42 \%)$, mainly pfannenstiel. The Verres needle was used to obtain pneumoperitoneum in $40(77 \%)$. Only one patient $(1.9 \%)$ had the operation converted to open cholecystectomy. Most patients, 47/51 (92\%), were discharged in 24 hours. The mean durations of various stages were: anaesthesia (110 minutes), pneumo-peritoneum (67.5 minutes) and reverse trendelenburg (47.8 minutes). The mean operating time reduced from 81 to 68 minutes in the last 20 patients. Complications were sore throat $11(21.6 \%)$, infection of the umbilical wound $3(5.9 \%)$, right shoulder tip pain $(3 ; 5.9 \%)$ and bile leak $1(2 \%)$. There was no peri-operative mortality.

CONCLUSION: Elective laparoscopic cholecystectomy can be performed with good results in patients with symptomatic gallstones in Accra. WAJM 2010; 29(2): 113-116.
\end{abstract}

Keywords: Laparoscopic cholecystectomy, Gallstones, Treatment outcome, Ghana.

\section{RÉSUMÉ}

CONTEXTE: cholécystectomie laparoscopique (CL) le traitement de choix pour les calculs n'étaient pas disponibles au Ghana jusqu'en 2005.

OBJECTIF : Rapporter l'expérience du Ghana de la cholécystectomie laparoscopique dans le traitement de galestones.

MÉTHODES: Dans une étude prospective de patients atteints de calculs biliaires, l'information a été obtenue sur la démographie, la durée des différentes étapes de l'opération, l'analgésie et de la complication des patients atteints de calculs biliaires. Tous les patients ont eu une anesthésie générale en utilisant une intubation endotrachéale relaxant musculaire, et de ventilation à pression positive intermittente. A quatre trocart technique standard et à la pression maximale de $14 \mathrm{mmHg}$ pneumopéritoine ont été maintenus pendant la chirurgie.

RÉSULTATS: Il y avait 50 femmes et deux hommes âgés de 17-72 ans (moyenne 44,2 années). Tous avaient des calculs biliaires symptomatiques traitées par intervalle de LC. Les indications principales étaient colique biliaire 23 (44\%) et une cholécystite précédente 15 (29\%). Il y avait des cicatrices de chirurgie abdominale antérieure au 22 (42\%), principalement Pfannenstiel. L'aiguille de Verres a été utilisée pour obtenir pneumopéritoine dans 40 (77\%). Un seul patient $(1,9 \%)$ si l'opération avait converti pour ouvrir une cholécystectomie. La plupart des patients, 47/51 (92\%), ont été libérés en 24 heures. Les durées moyennes des différentes étapes ont été: l'anesthésie (110 minutes), la pneumo-péritoine (67,5 minutes) et Proclive (47,8 minutes). La durée moyenne réduite de 81 à 68 minutes dans les 20 derniers patients. Les complications ont été des maux de gorge 11 (21,6\%), infection de la plaie ombilicale 3 (5,9\%), à droite la douleur pointe de l'épaule (3; 5,9\%) et la bile de fuite 1 (2\%). Il n'y avait pas de mortalité péri-opératoire.

CONCLUSION: une cholécystectomie laparoscopique peut être réalisée avec de bons résultats chez les patients ayant des calculs biliaires symptomatiques à Accra. WAJM 2010; 29(2): 113-116.

Mots-clés: cholécystectomie laparoscopique, calculs biliaires, issue du traitement, au Ghana.

Department of Surgery* and Anaesthesia , University of Ghana Medical School, P. O. Box 4236, Accra, Ghana.

Correspondence: J N A Clegg-Lamptey, Department of Surgery, University of Ghana Medical School, P. O. Box 4236, Accra, Ghana.

clegglamptey@hotmail.com

Abbreviations: BMI, Body mass indices; ECG, Electrocardiography; IPPV, Intermittent positive pressure ventilation; KBTH, Korle Bu Teaching

Hospital; LC, Laparoscopic Cholecystectomy; NIBP, Non-invasive blood pressure; STP, Shoulder-tip pain. 


\section{INTRODUCTION}

Laparoscopic cholecystectomy (LC) is the preferred treatment of gallstones. ${ }^{1}$ The advantages of shorter hospitalisation, early return to work, less pain and better cosmesis are well documented. ${ }^{2,3}$ The main drawbacks in setting up the service in resource-limited countries appear to be the initial capital investment and the steep learning curve. ${ }^{4}$

The procedure was not available to patients in Ghana until recently. Although the first LC in the country was performed by visiting surgeons in 1997, it was much later in 2005 that laparoscopic cholecystectomy was started in Korle Bu Teaching Hospital, one of the largest hospitals in West Africa.

A number of factors have been responsible for the late introduction of laparoscopic cholecystectomy in Ghana: the cost of the equipment, lack of the requisite operating skills and a failure to appreciate the cost-saving nature of the operations. Doubts have been raised as to whether LC is a cost-saving strategy in developing countries as LC tends to be comparatively expensive to the patient. This is due to the low cost of inpatient care and value of lost working time in developing countries. ${ }^{4}$ It may thus be cheaper spending extra days in hospital and losing days off work than paying extra for LC.

We report a prospective study of the first 52 patients undergoing Laparoscopic cholecystectomy over a period of two years and the lessons learnt.

\section{PATIENTS, MATERIALS, AND METHODS}

\section{Patients}

Patients diagnosed with symptomatic cholelithiasis were scheduled for interval LC and studied prospectively. Informed consent included explanation of the risk of conversion to open surgery. Exclusion criteria were patients with uncertain diagnosis and those with bile duct stones. There was no selection of patients with regard to obesity, previous abdominal surgery and previous cholecystitis.

\section{Data Collection}

Data entered into a proforma included demography, past medical history, co-morbidity, indication for surgery, details of anaesthesia, duration of the various stages of the operation (anaesthesia, pneumoperitoneum, operating time, dissection time, period of anti-trendelenburg) and highest intraabdominal pressure. Other details recorded were the method of laparoscopic access, trocar type/position used and any problems encountered with the equipment (like poor picture quality or faulty hand instruments). Postoperative information recorded included postoperative analgesia, pain scores (using a visual analogue scale of 0 to 10 ), date of discharge and complications. Data was compiled and analysed (mean, median, percentages) using Microsoft Excel and Epi-Info software.

\section{Anaesthetic Management}

All the patients fasted overnight. Majority of them $(41 / 52,79 \%)$ received midazolam orally as premedication. All received general anaesthesia using endotracheal intubation, muscle relaxant and intermittent positive pressure ventilation (IPPV). Induction was with propofol with the exception of two patients who received sodium thiopentone. The relaxant of choice was vecuronium.

Patients were maintained on oxygen/ air or oxygen/nitrous oxide and isoflurane (except in three patients) using a ventilator and a circle system with a carbon dioxide absorber. Intraoperative analgesics were fentanyl alone or fentanyl followed by pethidine. Muscle relaxation was reversed using a mixture of atropine and neostigmine. Monitoring consisted of heart rate, non-invasive blood pressure (NIBP), electrocardiography (ECG) and end-tidal carbon dioxide measurements.

All patients received intravenous infusion of about one litre of crystalloids during the surgery.

\section{Surgical Technique}

Rather than elevating the skin, two stay sutures were inserted into the rectus sheath for elevation during the initial blind insertion of Verres needle and trocar. The position of the Verres needle was con- firmed using the hanging-drop technique and checking the Verres intraperitoneal pressure against $\mathrm{CO}_{2}$ flow. Open placement of the initial port was used in patients with abdominal wall scars whenever the blind method was considered unsafe. All other ports were inserted under laparoscopic vision. A standard four-trocar technique was used in all cases $(10 \mathrm{~mm}$ umbilical, $10 \mathrm{~mm}$ epigastric, $5 \mathrm{~mm}$ subcostal midclavicular line, $5 \mathrm{~mm}$ anterior axillary line). The epigastric port was always situated to the right of the falciform ligament, same side as the gallbladder. A forward-viewing $0^{\circ}$ laparoscope was used for the first $41(78.8 \%)$ operations and $\mathrm{a} 30^{\circ}$ for the next 11(21.2\%).

To prevent the distended stomach from obscuring vision, a nasogastric tube was passed in all cases and removed at the end of the operation. Patients were tilted into reverse trendelenburg, with or without left side tilt, if visualising Calot's triangle was unsatisfactory during the operation. The maximum intra-abdominal pressure was set at $14 \mathrm{mmHg}$ and maximum $\mathrm{CO}_{2}$ flow rate of $2.51 / \mathrm{min}$ maintained throughout the operation. Calot's triangle was displayed by traction of the gall bladder fundus and the region of Hartmann's pouch. Dissection was carried out close to the gall bladder with curved dissecting forceps. Three titanium clips were applied to the cystic duct and the cystic artery before dividing them, leaving two clips proximally. The hook diathermy was then used in removing the gall bladder from its bed. Suction-irrigation was used in some cases to clear blood and bile. Standard sterile procedures were observed.

A disposable retrieval bag was used twice during the first five operations. All other equipment used, e.g. Verres needle, trocars, clip applicators and scissors were reuseable (autoclavable).

The gallbladder was removed through the umbilical port. At the end of the operation, all the wounds were infiltrated with $10-20 \mathrm{mls}$ of $0.25 \%$ plain bupivacaine. Diclofenac suppositories were inserted when not contraindicated. Apart from the umbilical port that was closed in two layers, all other wounds were closed in a single layer. 
Table 1: Indications for laparoscopic cholecystectomy in KBTH

\begin{tabular}{lr}
\hline Indication & Number(\%) \\
\hline Biliary colic & $23(44.2)$ \\
Cholecystitis & $15(28.8)$ \\
Recurrent cholecystitis \& & \\
biliary colic & $10(19.2)$ \\
Dyspepsia & $3(5.8)$ \\
Pancreatitis & $1(1.9)$ \\
\hline Total & $\mathbf{5 2 ( 9 9 . 9 )}$ \\
\hline
\end{tabular}

\section{RESULTS}

There were 52 patients - $50(96.2 \%)$ women and $2(3.8 \%)$ men - aged between 17 and 72 (mean 44.2 years, median 43 years). Their body mass indices (BMI) ranged from $17.4-45.4$. Fifteen (29\%) out of 52 were obese with a BMI $>30$.

Indications: All patients had interval LC. The main indications were biliary colic and cholecystitis (Table 1). None of the patients had asymptomatic gallstones. Two patients (male aged 27, female aged 28) had sickle cell disease. Other comorbidities were hypertension in $11(21.2 \%)$, diabetes mellitus in 5(9.6\%), gastro-oesophageal reflux disease in 3 $(5.8 \%)$, and peptic ulcer in another $3(5.8 \%)$.

Previous surgery: Twenty-two (42\%) of the patients had had previous laparotomies. There were pfannenstiel incision scars in $14(27 \%)$ patients, while

Table 2: Previous Abdominal Operations and Incision Scars

\begin{tabular}{lcl}
\hline Operation & Number $(\boldsymbol{\%})(\mathbf{N}=\mathbf{5 2})$ & Incision (Scar) \\
\hline Myomectomy & $4(7.7)$ & Pfannenstiel \\
1 Caesarean section $(\mathrm{C} / \mathrm{S})$ & $3(5.8)$ & Pfannenstiel \\
Laparotomy * & $3(5.8)$ & Lower midline \\
Appendicectomy & $2(3.8)$ & 1 Lanz, 1 paramedian \\
Hysterectomy (TAH) & $2(3.8)$ & Pfannenstiel \\
2C/S & $2(3.8)$ & Pfannenstiel \\
2 C/S \& Appendicectomy & $1(1.9)$ & Pfannenstiel + Lanz \\
3 C/S \& Appendicectomy & $1(1.9)$ & Lower midline + Lanz \\
C/S \& TAH & $1(1.9)$ & Pfannenstiel \\
3 C/S \& TAH & $1(1.9)$ & Pfannenstiel \\
C/S \& Laparoscopy & $1(1.9)$ & Lower midline \\
Tubal ligation & $1(1.9)$ & Lower midline \\
\hline Total & $\mathbf{2 2 ( 4 2 . 3 )}$ & \\
\hline
\end{tabular}

* Indications unknown others had lower midline and lanz incisions. The previous operations and resulting scars are shown in Table 2.

The Verres needle was used to obtain pneumoperitoneum in $40(77 \%)$ cases. Twelve $(23 \%)$, all of whom had previous abdominal wall scars, had insertion of the initial port under direct vision. There was one conversion to open cholecystectomy (1.9\%) on account of an

The duration of anaesthesia ranged from 65 to 200 (mean 110) minutes. The duration of $\mathrm{CO}_{2}$ pneumoperitoneum ranged from 35 to 130 (mean 67.5) minutes. Reverse trendelenburg, performed in 40 of the 51 patients, lasted between 20 and 115 (mean 47.8) minutes. Surgery time (from incision to wound closure) was 55122 (mean 81) minutes during the first half of the period; this was later reduced to 40-90 (mean 68) minutes in the last 20 patients.

Pain scores: Using a visual analogue scale of $0-10$, patients had pain scores between 1 and 5 (mean 3.5) two hours after surgery. Repeat pain scores after 24 hours were 0-4 (mean 2),

The majority of stones were mixed $24(46 \%)$. Others were pigment stones $17(33 \%)$, cholesterol stones $10(19 \%)$ and a mixture of pigment and cholesterol stones $1(2 \%)$.

Complications: Early complications were sore throat in $11 / 51$ (21.6\%), wound infection of the umbilical port in $3 / 51$ abnormal anatomy.
(5.9\%) and right shoulder tip pain in 3/51 (5.9\%). There was one patient (2\%) with bile leak from the common bile duct who needed Roux-en-Y choledochojejunostomy after three weeks. There was no peri-operative mortality.

Of the 51 who had laparoscopic cholecystectomy 47(92\%) were discharged 24 hours after surgery; 3 patients $(5.9 \%)$ were discharged after 48 hours (2 lived alone; 1 had a drain removed after 36 hours); one patient - a poorly controlled diabetic - was discharged after 72 hours. The mean duration of hospital stay after LC was 1.1 days.

\section{DISCUSSION}

Fifty-two patients with symptomatic gallstones had laparoscopic cholecystectomy at the Korle Bu Teaching hospital during a two-year period. There was one conversion to open surgery and no perioperative mortality. Morbidity was also satisfactory apart from a high rate of infection $(5.9 \%)$ at the umbilical port. Shoulder-tip pain was substantially less (5.9\%) compared to most reports (up to $35 \%)$.

Most of the patients were wellnourished women with high body mass indices (BMI). Many of them (22/52; 42\%) had a history of previous surgery with abdominal wall scars. Although the presence of abdominal wall scars was not considered a contraindication and did not influence the decision to perform LC, it influenced the method of initial puncture: 12 of the 22 patients with previous abdominal operations (56\%) had initial insertion under direct vision, while the Verres needle was used for all the patients without previous surgery as well as 10 patients with previous surgery. It has been suggested that it is preferable to use the left hypochondrium for the initial pneumoperitoneum when there is a risk of visceral injury from adhesions around the umbilicus..$^{5}$ The left hypochondrium was not used in this series because of the risk of damaging an enlarged spleen, not uncommon in Ghana. Although there were peritoneal adhesions in some of the patients with prior surgery they were easily dealt with and none of the operations was converted to open cholecystectomy on account of adhesions. 
Stay sutures on the rectus sheath to elevate the abdominal wall during insertion of the Verres needle and first trocar were used in all cases. Although it took longer to perform, there was a subjective feeling of having better control and less fear of damaging underlying viscera. It had the added advantage of facilitating closure of that wound, as tying the stay sutures often closed the fascial defect. We recommend this method of inserting the initial Verres needle and trocar, especially when operating on obese patients.

The conversion rate of $1.9 \%$ compares very favourably to other series from Africa that range from 5-18\%. ${ }^{6-10}$ This low conversion rate is likely to rise as other surgeons in this hospital begin to perform the procedure with its attendant steep learning curve. ${ }^{6}$

Significant bleeding occurs in $0.5 \%$ of $\mathrm{LC}$ and is one of the common reasons for conversion. ${ }^{11}$ There was significant bleeding from the cystic artery in two of our patients but it was easily controlled and did not result in conversion to open cholecystectomy.

Although there was no mortality there was a case of bile leak from the common bile duct managed by choledochojejunostomy. Other complications were minor. The high rate of wound infection of the umbilical port $(3 / 51,5.9 \%)$ is probably due to the fact that the gallbladder was removed through that wound without the use of a retrieval bag. There is controversy about the cause of shoulder-tip pain (STP) after LC. In this study the incidence of STP was low (5.9\%) compared to other series that were as high as $35 \% .{ }^{12}$ This complication, the aetiology of which is unclear, ${ }^{13-16}$ has not been studied in Africa and it is not clear if there are any racial differences affecting the incidence. Where STP is a problem measures that have been used with success include using lower intraabdominal pressures, ${ }^{13}$ reducing the amount of residual $\mathrm{CO}_{2},{ }^{14}$ and irrigation with saline ${ }^{15}$ or bupivacaine. ${ }^{16}$ None of these measures were used in this series.

One of the attractions of LC is early discharge from hospital and early return to activity. Although it is possible to perform day surgery LC, our patients were discharged after 24 hours because of the lack of home medical support and Family Physicians. Two patients requested to stay longer because they lived alone. The patients in this study were not selected with regard to previous abdominal surgery, obesity or previous cholecystitis. We, however, advise new laparoscopic surgeons to be selective in choosing their patients to avoid complications and a high rate of conversion to open cholecystectomy.

Laparoscopic cholecystectomy is currently not affordable to many patients in Korle $\mathrm{Bu}$ hospital because it is more than twice the cost of open cholecystectomy. The cost of LC would have been even higher, beyond the reach of most of our patients, if disposable instrument were used. In spite of the present cost a steadily increasing number of patients opted for the procedure during the period of this study. As patients begin to pay more realistic inpatient fees and the value of lost working hours increases, LC will hopefully become more costeffective. $^{4}$

\section{Conclusion}

Elective laparoscopic cholecystectomy has been performed with good results in patients with symptomatic gallstones in Accra. Patients with previous surgery as well as those with varying degrees of chronic inflammation after cholecystitis had LC with a low level of conversion to open surgery. The advantages of less pain and early discharge from hospital were evident.

\section{ACKNOWLEDGEMENTS}

We acknowledge the contribution of the team of doctors, nurses, students, anaesthetic assistants, and technicians. The corresponding author is very grateful to Mr. Doug McWhinnie of Milton Keynes NHS Trust (England), from whom he learnt many valuable 'tricks' for laparoscopic cholecystectomy.

\section{REFERENCES}

1. Nair RG, Dunn DC, Fowler S. et al. Progress with cholecystectomy: improving results in England and Wales. Br J Surg. 1997; 84: 1396-8.

2. Berggren U, Gordh T, Grama D. et al. Laparoscopic versus open cholecystectomy: hospitalization, sick leave, analgesia and trauma responses. $\mathrm{Br} \mathrm{J}$ Surg 1994; 81: 1362-1365

3. Keus F, de Jong JA, Gooszen HG et al. Laparoscopic versus open cholecys- tectomy for patients with symptomatic cholecystolithiasis. Cochrane Database Syst Rev. 2006; 4: CD006231.

4. Teerawattananon Y, Mugford M. Is it worth offering a routine laparoscopic cholecystectomy in developing countries? A Thailand case study. Cost Eff Resour Alloc. 2005; 3: 10.

5. Vilos GA, Ternamian A, Dempster J. et al. Laparoscopic entry: a review of techniques, technologies, and complications. J Obstet Gynaecol Can. 2007; 5: 433-65.

6. Baraza R. Laparoscopic cholecystectomy at the Nairobi Hospital: a personal experience with 42 cases. East Afr Med J. 2005; 82: 473-6.

7. Salam IM, Own A, Kareem NA et al. KA Laparoscopic cholecystectomy in the Academy Medical Centre, Khartoum, Sudan. East Afr Med J. 2005; 82: 10-3.

8. Patel SC, Bhatt JR. Laparoscopic cholecystectomy at the Aga Khan Hospital, Nairobi. East Afr Med J. 2000; 77: 194-8.

9. Muyanga J, Ghoor FO, Modiba MC. Laparoscopic cholecystectomy in black patients at Ga-Rankuwa Hospital: a feasibility study. Cent Afr J Med. 1999; 45: $176-8$.

10. Murphree S, Dakovic S, Mauchaza B. et al. Laparoscopic cholecystectomy in Zimbabwe: initial report. Cent Afr J Med. 1993; 39: 85-8.

11. Deziel DJ. Complications of cholecystectomy. Incidence, clinical manifestations, and diagnosis. Surg Clin North Am. 1994; 74: 809-23.

12. Esmat ME, Elsebae MM, Nasr MM et al. Combined low pressure pneumoperitoneum and intraperitoneal infusion of normal saline for reducing shoulder tip pain following laparoscopic cholecystectomy. World J Surg. 2006; 30: 1969-73.

13. Ibraheim OA, Samarkandi AH, Alshehry H. et al. Lactate and acid base changes during laparoscopic cholecystectomy. Middle East J Anesthesiol. 2006; 18: 757-68.

14. Jackson SA, Laurence AS, Hill JC. Does post-laparoscopy pain relate to residual carbon dioxide? Anaesthesia. 1996; 51: 485-7.

15. Barczyñski M, Herman RM. Lowpressure pneumoperitoneum combined with intraperitoneal saline washout for reduction of pain after laparoscopic cholecystectomy: a prospective randomized study. Surg Endosc. 2004; 18: $1368-73$.

16. Cunniffe MG, McAnena OJ, Dar MA et al. A prospective randomized trial of intraoperative bupivacaine irrigation for management of shoulder-tip pain following laparoscopy. Am J Surg. 1998; 176: $258-61$. 